\title{
Application of augmented reality as a means of interdisciplinary learning
}

\author{
Aplicación de la realidad aumentada como medio de aprendizaje interdisciplinario
}

\author{
Y. A. Mena-Vargas ; ; E. E. Millán-Rojas iD ; V. Sánchez-Castillo iD
}

\begin{abstract}
In this article, a review related to the application of augmented reality as a means of interdisciplinary learning deployed. The research developed to using two methods: exploratory and descriptive, with a systemic approach, using the following categories as origin: augmented reality, virtual reality, systems analysis, web, mixed reality and teaching. The search made in the Science Direct, Web Science, Google Academic and Scopus databases. One hundred and two scientific articles cataloged to develop the review. From the selected articles, the following questions were address: what are the conceptual vacuums present in augmented reality as a means of learning? how is augmented reality developed as a means of learning? what is the current discussion about augmented reality as a means of learning? and what are the relevant issues of augmented reality as a means of learning?. The implementations of the augmented reality in the academic subjects and the influential factors directly in their development were determined, in order to have a positive impact on the academic performance. As a general conclusion: the augmented reality improves academic interest and facilitates the development of teaching and learning processes.
\end{abstract}

Index Terms-Digital divide, Educational technology, Evolutionary computation, Information technology, Mobile learning.

Resumen-En el presente artículo se despliega una revisión de la cuestión relacionada con la aplicación de la realidad aumentada como medio de aprendizaje interdisciplinario. La investigación se desarrolló utilizando dos métodos: exploratorio y descriptivo, con un enfoque sistémico, utilizando las siguientes categorías como origen: realidad aumentada, realidad virtual, análisis de sistemas, web, realidad mixta y enseñanza. La búsqueda se realizó en las bases de datos Science Direct, Web Science, Google Académico y Scopus. Se catalogaron ciento dos artículos científicos para desarrollar la revisión. A partir de los artículos seleccionados se abordaron los siguientes interrogantes: ¿Cuáles son los vacíos conceptuales presentes en la realidad aumentada como medio de aprendizaje?; ¿Cómo se desarrolla la realidad aumentada como medio de aprendizaje?; ¿Cuál es la discusión actual sobre la realidad aumentada como medio de aprendizaje? y ¿Cuáles son los temas relevantes de la realidad aumentada como medio de aprendizaje? Se determinaron las implementaciones de la realidad aumentada en los temas académicos y los factores influyentes

This manuscript was sent on April 17, 2019 and accepted on September 25,2019 . This work was supported in part by the Systems Engineering program and the computer science, innovation and technology research group of the University of the Amazonia-GITUA- ".

Y. A. Mena-Vargas, is in the Systems Engineering program of the Faculty of Engineering of the University of the Amazonia, Florencia - Caquetá, Colombia, (email: ye.mena@udla.edu.co). directamente en su desarrollo, para tener un impacto positivo en el rendimiento académico. Como conclusión general se encontró: la realidad aumentada mejora el interés académico y facilita el desarrollo de los procesos de enseñanza y aprendizaje.

Palabras claves - Aprendizaje móvil, brecha digital, computación evolutiva, Tecnología de la información, Tecnología educacional.

\section{INTRODUCTION}

$\mathrm{I}_{\mathrm{r}}^{\mathrm{n}}$ $\mathrm{N}$ the following investigation, the development of augmented reality over the course of time, from its origin to the present time is studied. For this, the research project called "Augmented reality: didactic strategy to strengthen the teaching of the analysis of information systems" was taken as the point of origin. The aim is to contribute to the theoretical framework of the research, making a review on developments carried out in this field and with the use of certain tools associated with the augmented reality (AR).

Since the beginning of the AR have been developed and implemented multiple projects to achieve significant progress in this technology, however has achieved a strong line in academic developments and related to teaching and learning, also advances in training and simulations conducted in the business sector. The objectives of the research and developments of the AR is review in the topics related to the training of personnel at the level of education entities and at the business level. However, on other occasions the problem is not in the formation of people but in business processes, where it is necessary to simulate to analyze the consequences generated in advance to correct before carrying out its implementation and achieve optimal process. Taking the above into account, this was decide to develop a state of the art of the application of augmented reality as a means of interdisciplinary learning. Taking the above into account, This was decide to develop a state of the art of the application of augmented reality as a means of interdisciplinary learning, to show how the developments have been and what have been the difficulties encountered when carrying out the implementations and investigations. In addition, those characteristics to be take into

E. E. Millán-Rojas, a full-time professor of the Systems Engineering program at the Faculty of Engineering of the University of the Amazonia, Florence - Caquetá Colombia, (email: e.millan@udla.edu.co).

V. Sánchez-Castillo, full-time teacher in the Agroecologica Engineering program of the Faculty of Engineering of the University of the Amazonia, Florencia - Caquetá, Colombia, (email: ve.sanchez@udla.edu.co). 
account in the development of AR were collect in order to have a better performance.

The AR is often use for learning in different disciplines, which is why its benefits are considered in terms of generating greater concentration, attention and retention of information when using this medium for learning. In addition to this, the AR allows the people to learn in their own time, when they can do it from family or work environments, for this, it is necessary to meet the physical and technological conditions for their use. Learning can be interactively in a visual language, which can generate better attitudes and experiences [1]. The AR presents great acceptance and generates interest in the population, allowing people to come to want to use these tools and it is easy to use. In this way, it generates greater motivation to use this tool as a means of learning and this technology is promising in the context of education [2].

At present, several methods of teaching have arisen and one of them is the use of games, due to the interest generated in young people. Young people accept these applications quickly and include them in their daily routine. The above facilitates the handling of games based on AR or Virtual Reality (RV), and according to surveys conducted by [3] they improve the capture of information, being a key factor for learning. However, the difficulties encountered such as the interfaces used and the time of interaction generate problems and affect the variation of time when using mobile devices for AR or RV compared to sheets of paper or computers [4].

In the same way, we have also opted for 3D development and mixed reality, which tries to implement augmented reality and virtual reality synchronously to complement and generate better results in processes of sizing objects within a specific place or simulation of objects or sequences difficult to imagine or abstract with concepts [5]. In projects carried out in the field of medicine are evidence of the above where 3D software used for the simplification of concepts using variables, thus facilitating the learning of certain terms and knowledge of touch, which become difficult to understand. Technology appears as a determining agent in the significant advancement of learning, understanding and practice processes.

The developments of the AR achieve a positive effect on people. They change the perceptions of the environments and contribute to improving the understanding of reality. This contributes to the education of the population, offering facilities to develop better learning in certain complex areas. However, the population in general still does not have access to the highend devices necessary for the implementation of the technology. Work must continue on developments and access to the population in general.

\section{METHODOLOGY}

The present study carried out from the perspective of the exploratory and descriptive methods with a systemic approach. Applying the exploratory method, a search made in the databases of Science Direct, Web Science, Google Scholar and
Scopus of the significant experiences related to the application of the AR as a means of interdisciplinary learning. To carry out the search, the categories of augmented reality, virtual reality, systems analysis, web, mixed reality and teaching. Achieving obtain a universe of one hundred two (102) related items in different categories. After the search, we proceeded to perform the analysis based on the following research questions: what are the conceptual vacuums present in augmented reality as a means of learning? how is augmented reality developed as a means of learning? what is the current discussion about augmented reality as a means of learning? and what are the relevant issues of augmented reality as a means of learning? Based on these four questions, we used the descriptive method and made a detailed description of the experiences present in the work carried out and answered the questions within the framework of the established categories.

\section{RESULTS}

The concept of augmented reality proposed approximately 20 years ago, but even today, it has many limitations in the development of applications. This is due to the difficulty in the development of virtual information layers. These require the union of indices with the real environment and expert knowledge. The necessary data were generate to carry out an adequate follow-up, correct information of a precise place. However, difficulties arise due to the accuracy of the state of the scene and the work done by the user. In addition, a limited visualization of virtual objects can be cause in environments in which the information may be untimely and the processes were not corroborate correctly since there is no monitoring of their execution by the system [6].

\section{A. Conceptual vacuums present in augmented reality as a means of learning.}

In the investigations or projects related to the $\mathrm{AR}$ or the $\mathrm{RV}$ there are gaps present in the developments, in the implementations or tests carried out. Generating an impedement to continue with the development or diminishing the expected productivity with the implementation. With the new developments of augmented reality and virtual reality, researchers are looking for ways to apply these in the use of everyday life to achieve a positive effect. One of these investigations were relate to reading, where the aim was to find out if the reading speed changes when it is done with AR, RV in PC or on the LCD screen [4]. Although this study was only done in Chinese characters, which usually occupy more pixels compared to Latin letters. There are variations in the performance of reading in another language, needing to be explored in future studies, leaving the incognito if this will also be applied to other types of language or writing methods.

Although the development of applications of augmented reality for learning is already known, there is usually a deficit in the construction of this type of applications due to the ignorance of the development techniques. In many institutions there are no teachers with knowledge in programming for the development of AR and implement it in classrooms [7]. In addition to this, they are usually very expensive to develop, 
which implies a great expense on the part of the educational institutions.

A common mistake in people is the belief of the AR as responsible for improving learning. The above is reflected when $\mathrm{AR}$ is a tool to represent certain characteristics or objects explicitly. The AR allows the user to understand certain activities, topics or concepts. However, the objective sought is to allow a better interaction with information or data, through the implementation of virtual information visualized in reality using mobile devices and easy access to the end user [8].

The AR can be implement to support people in some work processes. However, there is a lack of maturity in terms of using it in industrial environments, applying it correctly. The AR were apply to specific processes, having consequently if you want to perform a different process; you must implement another type of support and a new development. The previous causes the little feasibility in the development of applications due to the separation made when being used in different processes [9].

There are also applications with limitations regarding the capacity of the building blocks (Modeling of objects) allowed to be use in the final model. This is a common error in the development software limiting the functionality of the application. For this reason, researchers like [10] propose to carry out the development in other environments such as Metaio, Metaio SDK and Unity3D. To allow better performance and expand to larger designs. In certain cases, in order to implement the use of augmented reality in the industry, it must be investigate how the technology will interact with the user to improve the company's processes [11].

With the deficiency of knowledge in the operators, has been chosen as a possible solution, the use of sensors and augmented reality to find out the performance of experts and create teaching materials for teaching in industries. However, there are difficulties with the sensors due to the cognitive effect created at the time of the capture of the object, which cannot be capture directly because there is no visual line with the object, which generates the capture manually. This causes loss of time and resistance in the industry to acquire this type of technology [12].

In the development of the applications of the AR at a general level, there are some faults, which must be solve before getting to implement the application. This generates discomfort or discomfort, some of these failures are inadequate recognition by the angle from which the image is captured and the light existing at the time of capture. In addition to this, when the technology is developed for teaching in the classroom, the following aspects should be taken into account: perform analysis on project-based learning, linking pedagogical aspects with technology, as well as when starting to build tools It is necessary to involve the end user and their perceptions to apply viable strategies [13].

In another study, it is propose [14] to take into account the scale of the area in which the developments will be carry out. In an 8 -foot by 8 -foot tracking area, it is usually small for certain developments, so the results found could not be apply in larger areas. The mentioned difficulty is generate when the projects are designed to be simple, generating few distractions in the virtual world, created to allow the participants to have a better concentration.

\section{B. Development augmented reality as a means of learning}

In the classrooms, many ways of transmitting knowledge to students have been implemented in such a way that they are interested in learning and improving their performance, for which studies have been carried out on which methods generate a greater performance in learning?. When taking into account this, tests have been apply to identify the obtained performance. Although the research [15] carried out was only apply to third grade students, it is not possible to generalize to higher grades. Nevertheless, some of the factors affecting performance are observe, such as learning anxiety and the effort made to understand. When reviewing the study, certain gaps were determined regarding the small number of people (sample) present for the tests and the exclusion of the population due to having different ages or academic levels.

There is a perception to be take into account, the use of augmented reality as a means of learning is not usually satisfactory for all people. Regarding its use, it is usually somewhat tired or boring according to studies [16]. One of the influencing factors is the interface used in the application, which generates an aspect of ease or difficulty for the user. For this reason, it is considere to develop intuitive interfaces to help users, helping them navigate the application in an easy and entertaining way.

In many of the research conducted on the AR, emphasis is place on the part of the application, but rarely, it is talk about how the type of content used affects. When the content turns out not to be attractive, it will have little interest for those who use it. In addition, it will not have a positive impact. Therefore, we must continue working to improve the contents and make them pleasant for end users. The previous thing must generate facility to use the application and its content [17].

You can get to witness the use of the AR as an efficient method, which helps with the retention of information and the improvement of learning spaces. However, there is a lack of motivation to use this technology as a means of learning in classrooms. The phenomenon occurs in schools as in universities. One of the reasons why it happens is due to the lack of qualified people to develop this type of content and application modeling [18].

In one of the developments made through the implementation of the AR using 3D glasses [19], there are several difficulties, physical effort, visualization through the device, as well as the difficulty to handle it. Users when asked about the use of this device, find it difficult to operate and invasive.

Another aspect to take into account in educational developments is the ability to process devices. The above due to the positive or negative effect generated by the speed with 
which the data was processed. This can be evidence in a virtual environment [20], which focused on the development of a robotic intelligent environment. This resulted in the reduction of consistency and performance reduction when multiple events occurred. Due to the processing speed used. However, this could be solve by increasing the number of components (services, agents), in order to extend the processing capacity and knowledge stored in the memory, making possible the scalability of the applications.

However, even with these gaps, an improvement has been achieved in those problems, a transitivity occurred in the developments and applications expanded over the years. In which this were found antecedents like the following works.

The AR is like a new trend in the population. Technology is being view favorably for learning by its didactic methods. Generating a better impact on people at the time of learning. The AR has a great relationship with virtual reality, except for being one in $2 \mathrm{D}$ and the other in $3 \mathrm{D}$. These new technologies generate new trends in which teachers must update and adapt their teaching methods to keep up with the use of new technologies and generate motivation in the learning classrooms [21].

The development of the technology in the beginning required some high costs in the use of hardware and software. However, it has tried to implement ways in which development is economic. To facilitate its commercial use and generate greater attractiveness for those who use it [22]. On the other hand, it allows generating adequate environments for learning.

The RA can be apply in mobile phones, commonly used by students, which allows the integration of technology in an easy way in classrooms. This generates satisfaction in the users when making use of those technological tools and using them as a learning environment. Sometimes it does not come to be smear because teachers do not have decorations of these topics for their development. However, more and more easy modeling techniques are develop, generating greater motivation in the students. For example, a framework called VEDILS is presented [23], a method of development and a tool, which allows the development of applications in four stages, where the development is implemented by, blocks, allowing ease in the teachers when developing their own applications.

At the application level, developments have been carry out in different fields, examples of which are software for education, medicine, companies, and games, among others. The development of augmented reality has occurred through the overlaying of information or layers of data in a real-time image, being already very popular and of great interest by the community. However, there is still much to investigate and improve in the different stages of development. One of the lines of research that is gaining strength is the so-called E-AR (Augmented Reality Ecological) which questions the theoretical assumptions of augmented reality [24].
Through the constant computational advance, developed, new applications generated to the use of the AR; one of them is the modeling of three-dimensional objects, which can be focused in different fields. The generated models can be explore online through two tools such as (Anatomography ${ }^{\circledR}$ and BioDigital ${ }^{\circledR}$ Human). Online tools allow users to interact in a dynamic way with objects that are not visible to the naked eye or difficult to access. Example: the human anatomy, the quantum world, the cell, among others, allowing the user to appropriate more knowledge by perceiving it visually and looking at it from different angles [25].

With the evolution of technology has been make to an application easy to use by MAR (Augmented Reality Mobile). Where these mobiles have the ability to be able to make use of learning human anatomy. The project was call HUMAR and I present a better performance when using this technological means as a means of learning [18].

In the field of medicine has been propose the use of 3D software for the simplification of concepts using variables, thus facilitating the learning of certain terms and tactile knowledge by making physical models of body parts, which arrive to be difficult to understand. It was determined as a significant advance in the process of learning, understanding and practical and tangible use [26].

The 3D animations have been an important experience in the development of 3D content for web applications or portals. 3D graphics have had a great development in the ease of making animations. Due to the existing problems with the "plugins" when wanting to make an animation work on the web, where errors often occurred and blocks due to incompatibilities. Although over time has improved the compatibility, achieving an integration and improvement in the experience captured by users. However under a small animation or 3D graphic there were a complex process make in multiple applications, APIs, platforms, among other tools to model the details of the graphic. In addition to this there are the standards called ISO for its development, which must be take into account at the time of its construction. All those graphics have improved under the application of Mayas and textures little by little, giving a better look to the graphics or animations [27].

It has also tried to develop a method by which you can make use of the 3D web without the need for many add-ons, or the use of a specific hardware and software component for its use. In addition, every time the machines used have better complements, which facilitate their execution. This were accept by students and the community in general due to the improved visualization of $3 \mathrm{D}$ models compared to $2 \mathrm{D}$. Now you have a better visualization of the objects and perspectives, generating pleasure in the person when interacting with technology [28].

The Application development is apply to teaching in different fields; one in particular is that of people with disabilities. The study [7] tries to integrate those people who are difficult to understand the topics, the speech to have a very limited vocabulary, attention and intellectual development, among other disabilities can be found in some classrooms. The AR 
application tries to assist people with disabilities to improve learning to interact independently with the tools. At the same time, it generates motivation and concentration when developing educational games, in addition to reducing the frustration in those students caused by not understanding the topics of study.

With the new developments and designs made in factories, companies or educational environments, it is usually the designer's job to perform the design inspection to check its correct operation. This is usually a delayed task by reviewing the details to prevent the occurrence of errors. For this reason, an AR application has been implement, which allows visual interaction with the designs. In addition, he looks at the object from different perspectives; he approves interacting with the designs with the movements of the hands. It can also be very useful for teaching design engineers with little experience [29].

When looking at certain objects or events, you cannot make a total capture of them and you can even get to lose part of the characteristics in the scene generated. In these cases, the AR is necessary in work areas. It serves as support and allows improving work performance. In addition to being able to implement with the use of a modified "Oculus Rift" [19], which tells the user what were the respective steps to complete. As a new development has also tried to perform the union of $\mathrm{x}$-ray vision together with augmented reality. The objective is to be able to accurately identify the position of certain objects hidden by the naked eye [30]. There are also developments where applications were create to perform the analysis of physical objects and generate models to then perform simulations of behaviors under certain variables and environments [31].

In the field of clinical learning, the use of augmented reality has been implemente together with another component called the magic mirror. By integrating these, you can perform a simulation of a form of scanning, allowing in the classrooms the observation of human anatomy in a macroscopic way. This application called AR MM makes a simulation of a real-time radiography, which allows a greater integration of the apprentices with the parts of the anatomy. The students see this as a significant advance in the learning process. Compared to the costs of physical practice and the purchase of books, this technology generates interest in the field of medicine [32].

Finally, in this section you can talk about the great interest in users for the games developed with this technology. Which use sensors and other components of the devices to provide a better experience and make them attractive to all types of people [33].

\section{Current discussion on augmented reality as a means of learning}

The discussions on augmented reality AR are diverse but can not be found in a linear way. Technologies have been develop over the last few years. However, developments a few years ago can contribute to the applications made today. Below are some of these developments.
Using augmented reality, a guiding mode has been propose to develop an inverted learning system, which can improve the academic performance of students. A method of teaching has already been proposed and put into practice, and it is the visualization of videos, which instruct the student with basic knowledge for the ease of understanding and the development of better-structured topics by teachers. Although this represents a problem for students with a slow learning pace. For this reason, using augmented reality approach provides the use of this by the student independently to be able again to check the points managed by teachers and so be able to advance to the pace of each student, generating a better performance [13].

Statements of understanding to make use of augmented reality as teaching can be see by comparing the average qualification of children before and after make use of this tool [34]. For experts, it is essential to provide the knowledge to trainees. Although problems arise at the time of doing so, and impede understanding. While an expert this very qualified on the topics to teach, they usually have difficulty transmitting information, due to the use of unknown terms or the omission of topics by the expert to create them unimportant. However, even taking into account the foregoing the analysis determined that the technology based on sensors AR as a promising solution to improve the training of apprentices [12].

The mixed reality to be implement in factories of learning and training improves the understanding of concepts and the development of motor skills. Furthermore, this type of environments has great flexibility and adaptability. In consequence of not being dependent on the hardware. Allowing a better experience when viewing environments, processes and methods do not exist in the physical part of the device. In addition, the development of these applications is of importance in future fields to open new opportunities, to represent each time a greater need [35].

Another project develops virtual reality on a robotic intelligent environment through a multimodal interaction architecture. The development of tasks or processes with little intervention from a human being, using semantic agents and web services to store information of objects and evaluate actions in virtual scenarios [20].

Relevant aspects in the use of augmented reality in the field of manufacturing are analysis of manufacturing processes, the integration of designs and the experience of users, to qualify the productivity of processes. In addition to this, the use of genetic algorithms to optimize designs based on the performance indicators (KPIS). Allowing comparison of different designs and define which can lead to better performance in production. In addition, there has also been the implementation of simulations, which try to describe which designs produce better performance. This were complete by a focus of analysis immersive, which tries to improve the production, allowing analyzing performance and spatiality. This is used a simulator for advanced manufacturing (SAM) which allows to simulate production lines designs. This Simulator were use in computers from above table, but want to implement and make comparisons of designs and combine them with the experience of users [5]. 
Another element to discuss factors of locomotion of the enthronement of AR users, to offer a better satisfaction and experience when using them. For this work [14] is an analysis of the different skills or skills possible to use within environments. In addition to the ease with which it can be used by users, due to the implementation of this type of environments in different fields with only a few adjustments. Where some of these fields could be learning through visualization of events difficult to see with the naked eye in real life, everything would depend on the application.

Mixed reality (MR) is a field encompassing the augmented reality (AR) and virtual reality (VR). Which is a technology integrator to mesclar aspects the real world with the virtual world. It allows the visualization of features of the world real in more detail, allowing better interaction human-computer. This would allow an improvement to develop processes of maintenance and inspection with the use of this technology. Currently maintenance processes were develop manually through several steps. By which implementation of the MR performance would generate in those fields as the aviation industry [36]. The factories implements of learning and training improves the understanding of concepts and the development of motor skills. Furthermore, this type of environments has great flexibility and adaptability. Consequently, not be dependent of the physical hardware. Allowing a better experience when viewing environments, processes and methods do not exist in the physical part of the device. The development of these applications will be of great importance in field's future by opening new opportunities to represent each time a greater need [35].

By teaching, one of the best ways to capture knowledge and improving skills is through simulations. The above allows acquiring skills through repeated practice, helping to not make mistakes. This is a methodology, which should be use for the improvement of the competences in learners both undergraduate as a postgraduate, due to lack of experience and a decoction of the different scenarios to occur may present. You can see example of this in medicine, with the need for simulations to prevent damage to human life and create realistic environments in the training of future doctors [37].

With the development of AR or RV oubicacion geographical location-based applications [38], a method of evaluating immersion in these technologies. For this, they develop ARI questionnaire, which would make it possible to assess the cognitive and emotional aspects generated by the user using the application. To make the respective tests was determined as the ARI tool is useful to evaluate the aspects of diving, in the development of AR the location focused on learning-based [39]. Besides using this tool, AR difficulties wer not generate by the difference of sex, which does not generate a situation of exclusion among students, both men and women. Besides this, it generates a positive attitude in students and improves the performance of the same. Finally has a great acceptance by the students, which have had the opportunity to learn by using this medium [40].
Trying to apply it learning to plan and conduct processes during its development. This is due to the extra motivation, generated in the students. Motivation is one of the factors to intervene with the performance, either positive or negative. In addition to the time to implement the addition of technology can be seen a negative effect on the performance of learning. For the proper study, were multiple prototypes, which increasingly had more complex and could be implemented in a interdisciplinary way, applying in different tasks or issues. También se llegó notar una mejora en los estudiantes mediante el uso de los prototipos, debido a su asistencia, la cual permitía una comprensión de conceptos e influyo en la motivación [41]. One of the ways in which is has teaching implementation, is through games with certain content or topics, which should be learning through the development of gaming activities. This allows improving cultural understanding of the languages, as well as the skills of language, as the communication. In addition to this, one of the functions of the game was the ability to communicate with strangers, which allowed improving the capacities of communication with other people from the language to learn [42].

The AR were take as a new trend, which is optimistic about use-applied learning. This generates the need to adapt to these new technologies and integrate them into the classroom teachers. To create new expectations and even a stronger effect of learning in students [21]. With the implementation of AR, you want to know the opinion of the students in the development of mobile applications, to improve the understanding of the issues and the difficulty. Although at the time of the testing was to identify nonconformity, although he had great accept students help in learning, were those who did not agree and they were not satisfied with the implementation of this in the classroom of class. Those students who mentioned disagree, was by the fact of not having technologies and was an impediment for them. However, in terms of other criteria implementation of augmented reality came to view positively. Aspects as to be able to use this application extra class, increased interest and motivation, improve attention and attracts students to the activities, they can be see in the students. Therefore, if you consider the great acceptance, acceptable is the implementation in learning environments [43].

To evaluate the components of the connectivism in the learning environment, seeks to improve the learning and training of experts. Related to the need for development of certain factors to certify the suitability of the environment in augmented reality, improving in this way the scientific culture. Where a research tool where it was determined the improvement of a culture through four components was use to conduct the assessment [44]. Doubts about whether this mathematics may apply in certain fields of knowledge, including for upper grade students have also emerged. Taking into account the above and performing tests and developments of augmented reality to apply them in the field of complex materials or level academic superior arrived at conclusion of the fact of having a positive effect in the opinion of the students. Using augmented reality, you can see 3D objects, which in the hood of the mathematics is very helpful for the abstraction and the interaction, allowing a better understanding of certain 
concepts or events were explain in this field. By which concluded technologies 3D can enhance the teaching and learning of mathematics in higher education [45].

Even have been implementing methods of collaborative and autonomous learning promoted by the AR using tools. These allow workshops and practices without the need for a teacher. Using three applications learning activities could be undertaken. In the view of the participants, the tools (ELECT3D, ELECTAR_NOTES, and ELECTARMANUAL) used performance enhancing and its use is satisfactory, in addition to helping understand difficult concepts easier to represent by animations or images. Although there is great similarity in applications, considering its easy use according to participants [46].

Augmented reality has had a great evolution with the passing of time, so with the constant changes are as foundations the teaching of some theoretical and composing concepts and layer in augmented reality, to be able to deploy bases in the digital literacy and be able to implement or carry out projects on the technologies available. Still emerging problems and challenges for both instructors and students to meet different difficulties using these new technologies available [47]. On the other hand, it may provide very satisfactory results to be use for the teaching of children walking age. This were reflect in a large increase in the average of the same rating. According to the given conclusion, the cause of this improvement is the tool, which generates more easily in the understanding of the issues for children [34]. Also discussed the integration of autonomy in augmented reality. In addition to this an easy way to develop assistance given to the user by using the analysis made by the AR of a video. This shows how to proceed. With the recognition of the environment and the steps to take, to take video as a reference [6].

The trainings were make in two sections, to theoretical and practice. The AR may be very viable when it comes to training. Which generates true cost and time to the people, but with the use of augmented reality all these processes can be perform in less time and cost, which becomes very beneficial and pleasant from the perspective of the people. However, the existence of certain processes of codification of the AR, which can generate higher cost compared to do, so without the use of technology must be take into consideration. This occurs in some cases or processes which require little time, cost and effort of physical form. The AR development costs may be higher. With this in mind the type of processes and fields applied to the augmented reality to generate greater benefits at the time of use it should be contemplate [22]. In addition, there is a massive acceptance of augmented reality in the population. In addition to the opinion given, to be a good way of learning. Where would the population agree to use and disseminate the information on AR [2].

\section{Relevant topics of augmented reality as a means of learning}

When to publicize the importance of investigations or projects to develop, looking through different approaches. They evaluate the effect generated in the person, the acceptance given by the people, the utility that has that development on the environment, among others.

In certain types of materials or subjects given to students or students can be observe difficulties trying to understand abstract concepts in tree dimensions. An example of this is the course of structural analysis, which refers to this type of topics generate certain difficulties. For this reason raises a pedagogy, which implements the use of $\mathrm{AR}$ and interactive $3 \mathrm{D}$ designs to have a better perception of objects. The development of this application generates great interest to students and generates a better understanding of the concepts taken from books, unlike the books to the only power displayed in 2 dimensions to be drawn, which becomes a little difficult of understand. In the end, it was complete; learning through this kind of pedagogy was a very good way to understand certain issues due to their abstraction, which could be see. In addition, to repeatedly perform planned exercises [16].

You can get to know themes such as the implementation of an augmented reality system to complement the process of dental surgeries, integrating components such as tracking systems, medical imaging, surgical instruments and the computer for the navigation in real time. Allowing display of a visual way to users procedures, to generate security in this way in the same. In addition, the implementation of AR would perform best surgeries with greater security and less risk in comparison with common visual reality [48].

The application in the teaching of languages as the English didactics. We found two ways to do it, one guided form and other free or global form in which it knew if I had time to learn either free or guided difference. As results became complete both forms had a positive effect on the students, but there were factors, which intervened in their learning when to learn guided or free, due to the involvement of the effort made in the mind. Although the effort generated interest or challenges for some, for others it was tiring and stressful so it came to be inversely productive this type of development [15].

On the other hand in work processes, such as carrying out maintenance work, which have consequences in these tasks to occur errors. According to the survey conducted for four people with about 20 years of experience, unveiled his opinion arguing about their work. How it could help the implementation of augmented reality in these works. Increasing efficiency and decreasing the amount of errors, which have an effect on the cost. By the conclusion of integrating in the maintenance industry, which was, however, both subjects should be contemplate in the management of data, if necessary analyse information, as you must be capture or displayed and as it is controlled is dent information systems [11].

The creation of textbooks is one of the forms used for teaching in lower or higher grades. In addition to complement have been implemented using AR with books, allowing use in an interactive way and attract the attention of students. At the time of developing AR books should have students or audience for which target books make designs to different answer. With this 
development were presume to better learning in children and improvement in their communication skills, to have a better development and increased sociability. This is done using different ways to carry out the work, as she is done in a group sharing the same device. In addition to find the implementation of the JRC methods in development in the implementation of AR to close the gap there between these two [8]. Taking into account the above are results of other developments in which augmented reality can be used for teaching to children over four years to improve their understanding of numbers and vowels, helping you to understand more easily some of the themes commonly confused for them.

Augmented reality enhances information in student retention when used as learning tool. This can be visualize by having as a result a high scholastic average, with respect to the previous. This was check by doing a thorough comparison of the average academic before and after using the tool. It were obtain as a result, students of significantly improving [49].

Augmented reality has multiple processes for applications with an interesting interface and easy-to-manipulate user content, this type of qualities facilitate the user better performance. This is base on the perception of augmented reality. In certain cases, do not perform well information studies and the development of content, being interactive to generating user perceptions of pleasure. Therefore, it were consider as a great help-augmented reality. This is achieved when the development is done properly both at the level of interface and content. In this way, it could be apply to different fields of learning [50].

Some teachers and designers have tried to make use of the technology and implement it in learning in different fields. Developed a project with an augmented reality game, where intends to meet the acceptance of students who showed great interest. Although there has been a lack of completion of the system [51].

With the advancement of technology has emerged the proposal for the implementation of this in the classroom to enhance learning and although it is already applied and research on the performance of the students have been using augmented reality to understand issues which become complex, we have seen academic improvement. In addition still has in mind, affects how learning to those factors as static or dynamic content is display. Although according to the results of the study students preferred content dynamic to be easy to understand concepts [17].

It is for tools, which allow you to promote the development of AR applications to apply them in the classroom. This in turn could be implement in an interdisciplinary manner to be teachers who develop applications according to the topics covered. In addition to this, students have teams to develop activities of AR due to the capacity of the mobile audience in classes [23]. Improve the average academic students and certain academic subjects with difficulty understanding can be achieve. Thus generating a greater achievement in the academic field [49].
One of the biggest impacts generated by the tools of digital three-dimensional modeling is the use in learning environments. At that time, students can navigate virtual around models, being rather pleasant and generating interest to students by its cost and flexibility according to their views [25].

He has been the development of objects using augmented reality for reduced form modelling and at low cost. This development were accomplished by taking points of reference by means of sensors demarcating the image or video captured, thus makes a recognition of the object to which it is aimed. First, there must be a design with parameters to be apply to the object focused by the camera, and then overlap it with the view actual image. To this effect of envelope put nonexistent virtual objects by means of a video or photo at that moment is call-augmented reality. Bringing non-existent things on those existing or take existing things to a non-existent physical environment. Thus, this can be apply in the development of objects magnetically in engineering through simulations before you get to build it [52]. In this way, it has also sought to implement processes of simulations in the field of dentistry, used with the complementation of other instruments to make a display of the processes carried out in surgery. It can also be use as a means of learning to make practices to improve technique and have more experience in these processes, having a positive effect of safety and lower risk [48].

An education-related project, evaluated an educational program for pedestrian navigation, which makes use of the augmented reality through the application of e-learning and $\mathrm{m}$ learning. Where you want to know which of the two has greater acceptance in people and facilitates learning. The results of that investigation were in favour of m-learning due to their greater interaction. This was determined to have best m-learning results. In addition to this, they wanted to know the effectiveness of the use of technology such as the AR, MPN and mapping artifacts in teaching [53].

\section{CONCLUSION}

With reference to all those investigations and projects it can be inferred that there is a large deficit in the training of teachers or people in the management of applications for educational purposes, in such a way that do not know how to perform a correct application, or how to develop them. However, for the development of applications of AR, VR or MR, is usually study that it should be an expert and have multiple knowledge in these fields, there are forms that facilitate the development of those with lower strength and this is due to the contribution provided by the pe rsonas to facilitate and provide multiple learning methods. This seeks the inclusion of all people, regardless of physical or cognitive difficulties they may have, to provide opportunities to learn and participate in different aspects.

The use of web applications has been a great improvement in ease of use them, due to connection errors that used to occur in a start to run, but these have now been resolved and proposed new services, methodologies and ways of developing applications. There has been an evolution so large that they can 
find applications of great robustness, which tend to be many aid when required to learn something. Although certain services flooring be paid, some free you can also find in case of not having the monetary ease, becoming a great opportunity to use the technologies developed and learn a variety of topics.

With the implementation of machines, platforms and other technological elements for teaching has been observe to have a positive effect on learning. As for example the use of augmented reality as a learning tool where they develop applications with interactive, eye-catching graphics and sequences of activities has been obtain results of improvement in grade point average, in addition to observe a greater concentration and attention in the development of the activities. Though clarifies that the use of these technologies replaces the teachers, because they guide the student and may develop or recommend the content that created suitable [1].

Education is an issue which has sought have better results, where people are better qualified and can develop in a way appropriate in environments that. Why are investigations of the different issues that may affect the development of cognitive ability of person, to determine whether the thematic content, the environment of learning, emotional and inter alia State have a effect on learning or understanding of academic issues. On the other hand technology tools focused on learning or ICT (information or communication technologies) allow learning without gender discrimination, removed a barrier that exists in certain environments or societies [40].

In relation to this review, you can find several articles, which talk about the implementation of AR in education due to its benefits, where the view is that is, should have a greater implementation in the classroom [54]. Still with so many results that demonstrate a positive impact on the academic, not has been chose to make use of these technologies today, there is still the lack of application.

The focused augmented reality application extends it to facilitate learning and to generate a better understanding in the academic aspect. It is still very little information on its focused development to systems analysis teaching, in fact there are few issues related to this issue, being a very good opportunity to conduct a study in this field. Since this is one of the fundamental issues in the teaching of certain careers of systems engineering systems analysis, to identify physical issues of our environment, making relations abstract when not can be display. Oak is believe that augmented reality can help in the aspect to be use for the teaching of analysis systems, due to their wide application. It is propose as a possible future work.

\section{REFERENCES}

[1] C. Merino, S. Pino, E. Meyer, J. M. Garrido y F. Gallardo, «Realidad aumentada para el diseño de secuencias de enseñanza-aprendizaje en química.» Educacion quimica, vol. 26, n² 2, pp. 94-99, 2015. Available from http://www.scielo.org.mx/scielo.php?pid=S0187893X2015000200004\&script=sci_arttext\&tlng=en
[2] R. Mendoza , S. Baldiris y R. Fabregat, «Framework to heritage education using emerging technologies.,» Procedia Computer Science, vol. 75, nº 1, pp. 239-249, 2015. doi:10.1016/j.procs.2015.12.244.

[3] M. S. Calabor, A. Mora y S. Moya, «Adquisición de competencias a través de juegos serios en el área contable: un análisis empírico.,» Revista de Contabilidad, vol. 21, $\mathrm{n}^{\circ}$ 1, pp. 38-47, 2018. doi:10.1016/j.rcsar.2016.11.001.

[4] L. P. Rau-P, J. Zheng, Z. Guo y J. Li, «Speed reading on virtual reality and augmented reality.,» Computers \& Education, vol. 125, $\mathrm{n}^{\circ} 1$, pp. 240-245, 2018. doi:10.1016/j.compedu.2018.06.016

[5] D. Herr , J. Reinhardt , G. Reina , R. Krüger , R. V. Ferrari y T. Ertl , «Immersive Modular Factory Layout Planning using Augmented Reality,» Procedia CIRP, vol. 72, $\mathrm{n}^{\circ}$ 1, pp. 1112-1117, 2018. doi:10.1016/j.procir.2018.03.200.

[6] N. Petersen y D. Stricker, «Cognitive augmented reality,» Computers \& Graphics, vol. 53, nº 1, pp. 82-91, 2015. doi:10.1016/j.cag.2015.08.009.

[7] C. W. Chen , Y. M. Huang, C. Y. Lin, H. C. Chai , J. Y. Wang y C. J. Chen, «Augmented reality in educational activities for children with disabilities.,» Displays, vol. 42, $\mathrm{n}^{\circ}$ 1, pp. 51-54, 2016. doi:10.1016/j.displa.2015.02.004

[8] H. Alhumaidan, P. Y. Lo-K y A. Selby, «Co-designing with children a collaborative augmented reality book based on a primary school textbook.,» International Journal of Child-Computer Interaction, vol. 15, no 1, pp. 24-36, 2018. doi:10.1016/j.ijcci.2017.11.005

[9] F. Suárez-Warden , E. G. Mendívil , C. A. Rodríguez y S. GarciaLumbreras, «Suárez-Warden, F., Mendívil, E. G., Rodríguez, C. A., \& Garcia-Lumbreras, S. Assembly operations aided by augmented reality: an endeavour toward a comparative analysis.,» Procedia Computer Science, vol. 75, $\mathrm{n}^{\circ} \quad$ 1, pp. 281-290., 2015. doi:10.1016/j.procs.2015.12.249

[10] P. Hořejší, «Hořejší, P. Augmented reality system for virtual training of parts assembly.,» Procedia Engineering, vol. 100, n 1, pp. 699-706, 2015. doi:10.1016/j.proeng.2015.01.422

[11] I. F. del Amo , J. A. Erkoyuncu , R. Roy y S. Wildi, «Augmented Reality in Maintenance: An information-centred design framework.,» Procedia Manufacturing, vol. 19, $\mathrm{n}^{\circ} \quad 1, \quad$ pp. 148-155., 2018. doi:10.1016/j.promfg.2018.01.021

[12] B. H. Limbu , H. Jarodzka, R. Klemke y M. Specht, «Using sensors and augmented reality to train apprentices using recorded expert performance: A systematic literature review,» Educational Research Review, vol. 25, no 1, pp. 1-22, 2018. doi:10.1016/j.edurev.2018.07.001

[13] S. C. Chang y G. J. Hwang, «Impacts of an augmented reality-based flipped learning guiding approach on students' scientific project performance and perceptions.,» Computers \& Education, vol. 125, $\mathrm{n}^{\circ} 1$, pp. 226-239, 2018. doi:10.1016/j.compedu.2018.06.007

[14] E. Bozgeyikli , A. Raij , S. Katkoori y R. Dubey, «Locomotion in Virtual Reality for Room Scale Tracked Areas.,» International Journal of Human-Computer Studies., vol. 122, $\mathrm{n}^{\circ}$ 1, pp. 38-49, 2018. doi:10.1016/j.ijhcs.2018.08.002

[15] T. C. Hsu, «Learning English with augmented reality: Do learning styles matter?.,» Computers \& Education, vol. 106, n 1, pp. 137-149, 2017. doi:10.1016/j.compedu.2016.12.007

[16] A. H. Behzadan, A. Chen, Y. Turkan , R. Radkowski y A. KarabulutIlgu , «Mobile augmented reality for teaching structural analysis.,» Advanced Engineering Informatics, vol. 34, $\mathrm{n}^{\circ}$ 1, pp. 90-100, 2017. doi:10.1016/j.aei.2017.09.005

[17] C. Diaz , M. Hincapié y G. Moreno , «How the type of content in educative augmented reality application affects the learning experience.,» Procedia Computer Science, vol. 75, n 1, pp. 205-212, 2015. doi:10.1016/j.procs.2015.12.239

[18] S. S. Jamali , M. F. Shiratuddin, K. W. Wong y C. L. Oskam, «Utilising mobile-augmented reality for learning human anatomy.,» ProcediaSocial and Behavioral Sciences, vol. 197, $\mathrm{n}^{\circ}$ 1, pp. 659-668, 2015. doi:10.1016/j.sbspro.2015.07.054

[19] A. Syberfeldt , O. Danielsson , M. Holm y L. Wang , «Visual assembling guidance using augmented reality,» Procedia Manufacturing, vol. $1, \quad \mathrm{n}^{\circ} \quad 1, \quad$ pp. 98-109, 2015. doi:10.1016/j.promfg.2015.09.068 
[20] O. Adjali , M. D. Hina, S. Dourlens y A. Ramdane-Cherf, «Multimodal fusion, fission and virtual reality simulation for an ambient robotic intelligence.,» Procedia Computer Science, vol. 52, $\mathrm{n}^{\circ}$ 1, pp. 218-225, 2015. doi:10.1016/j.procs.2015.05.060

[21] G. A. González , «How to include augmented reality in descriptive geometry teaching.,» Procedia Computer Science, vol. 75, $\mathrm{n}^{\circ} 1$, pp. 250256, 2015. doi:10.1016/j.procs.2015.12.245

[22] H. Ramírez , E. Mendoza , M. Mendoza y E. González, «Ramírez, H., Mendoza, E., Mendoza, M., \& González, E. Application of augmented reality in statistical process control, to increment the productivity in manufacture.,» Procedia Computer Science, vol. 75, n 1, pp. 213-220., 2015. doi:10.1016/j.procs.2015.12.240

[23] J. M. Mota , I. Ruiz-Rube , J. M. Dodero y I. Arnedillo-Sánchez, «Augmented reality mobile app development for all.,» Computers \& Electrical Engineering, vol. 65, $\mathrm{n}^{\mathrm{o}}$ 1, pp. 250-260., 2018. doi:10.1016/j.compeleceng.2017.08.025

[24] V. Raja y P. Calvo, «Augmented reality: An ecological blend.,» Cognitive Systems Research, vol. 42, $\mathrm{n}^{\circ}$ 1, pp. 58-72., 2017. doi:10.1016/j.cogsys.2016.11.009

[25] G. Arrondo , J. Bernacer y L. D. Robredo , «Visualización de modelos digitales tridimensionales en la enseñanza de anatomía: principales recursos y una experiencia docente en neuroanatomía.,» Educación Médica, vol. 18(4), $\mathrm{n}^{\mathrm{o}}$ 1, pp. 267-269, 2017. doi:10.1016/j.edumed.2016.06.022

[26] L. A. Tafur-Betancourt, F. E. Lema , G. Mar-Milla , A. Londoño y J. R. Navarro-Vargas , «From pharmacokinetics to pharmacodynamicsAre we ready for 3D software,» Revista Colombiana de Anestesiología, vol. 45, $\mathrm{n}^{\mathrm{o}} 4$, pp. 335-339, 2017. Available from http://www.scielo.org.co/scielo.php?script= sci_arttext\&pid=S0120-33472017000400335

[27] A. Evans , M. Romeo , A. Bahrehmand , J. Agenjo y J. Blat , «3D graphics on the web: A survey.,» Computers \& Graphics, vol. $41, \mathrm{n}^{\circ} 1$, pp. 43-61, 2014.

[28] H. Olmedo , K. Olalde y B. García, «MotoStudent and the Web3D.,» Procedia Computer Science, vol. 75, $\mathrm{n}^{\circ}$ 1, pp. 84-94, 2015. doi:10.1016/j.procs.2015.12.220

[29] D. Mourtzisa , V. Zogopoulosa y E. Vlachoua , «Augmented Reality supported Product Design towards Industry 4.0: a Teaching Factory paradigm.,» Education \& Training, vol. 2351, nº 1, p. 9789, 2018. doi:10.1016/j.promfg.2018.04.018

[30] F. Liu y S. Seipel, «Precision study on augmented reality-based visual guidance for facility management tasks.,» Automation in Construction, vol. 90, $\mathrm{n}^{\circ}$ 1, pp. 79-90, 2018. doi:10.1016/j.autcon.2018.02.020

[31] J. M. Huang, S. K. Ong y A. Y. Nee, «Visualization and interaction of finite element analysis in augmented reality.,» Computer-Aided Design, vol. 84, n 1, pp. 1-14, 2017. doi:10.1016/j.cad.2016.10.004

[32] D. Kugelmann, L. Stratmann , N. Nühlen, F. Bork, S. Hoffmann , G. Samarbarksh y N. Navab, , «An augmented reality magic mirror as additive teaching device for gross anatomy.,» Annals of AnatomyAnatomischer Anzeiger, vol. 215, $\mathrm{n}^{\circ}$ 1, pp. 71-77, 2018. doi:10.1016/j.aanat.2017.09.011

[33] F. Z. Eishita y K. G. Stanley, «The impact on player experience in augmented reality outdoor games of different noise models.,» Entertainment Computing, vol. 27, $\mathrm{n}^{\circ}$ 1, pp. 137-149., 2018. doi:10.1016/j.entcom.2018.04.006

[34] E. Cieza y D. Lujan , «Educational Mobile Application of Augmented Reality Based on Markers to Improve the Learning of Vowel Usage and Numbers for Children of a Kindergarten in Trujillo.,» Procedia computer science, vol. 130, $\mathrm{n}^{\circ}$ 1, pp. 352-358., 2018. doi:10.1016/j.procs.2018.04.051

[35] M. Juraschek , L. Büth , G. Posselt y C. Herrmann, «Mixed Reality in Learning Factories.,» Procedia Manufacturing, vol. 23, n ${ }^{\circ}$, pp. 153158, 2018. doi:10.1016/j.promfg.2018.04.009

[36] H. Eschen , T. Kötter , R. Rodeck , M. Harnisch y T. Schüppstuhl , «Augmented and Virtual Reality for Inspection and Maintenance Processes in the Aviation Industry.,» Procedia Manufacturing, vol. 19, pp. 156-163, 2018. doi:10.1016/j.promfg.2018.01.022

[37] L. V. Ávila-S, M. B. Gall-S, A. G. Sánchez-J, I. M. Rangel-M, I. T. Lugo-M, B. D. Guerrero-A y A. M. Méndez, «Diseño y validación de un simulador híbrido de paracentesis.,» Educación Médica, vol. 20, n 1, pp. 37-41, 2018. doi:10.1016/j.edumed.2017.10.033

[38] z. Lv, x. Li y W. Li , «Virtual reality geographical interactive scene semantics research for immersive geography learning.,» Neurocomputing, vol. 254, $\mathrm{n}^{\mathrm{o}} \quad 1, \quad$ pp. 71-78, 2017. doi:10.1016/j.neucom.2016.07.078

[39] Y. Georgiou y E. A. Kyza, «The development and validation of the ARI questionnaire: An instrument for measuring immersion in locationbased augmented reality settings.,» International Journal of HumanComputer Studies, vol. 98, $\mathrm{n}^{\mathrm{o}}$ 1, pp. 24-37, 2017. doi:10.1016/j.ijhcs.2016.09.014

[40] J. C. Almenara, J. B. Osuna y M. Obrador, «Realidad aumentada aplicada a la enseñanza de la medicina.,» Educación Médica, vol. 18, n 3, pp. 203-208., 2017. doi:10.1016/j.edumed.2016.06.015

[41] D. Sampaio y P. Almeida, «Pedagogical strategies for the integration of Augmented Reality in ICT teaching and learning processes.,» Procedia Computer Science, vol. 100, $\mathrm{n}^{\mathrm{o}}$ 1, pp. 894-899, 2016. doi:10.1016/j.procs.2016.09.240

[42] Y. Liu , D. Holden y D. Zheng, «Analyzing students' language learning experience in an augmented reality mobile game: an exploration of an emergent learning environment.,» Procedia-Social and Behavioral Sciences, vol. 228, $\mathrm{n}^{\mathrm{o}} 1$, pp. 369-374, 2016 doi:10.1016/j.sbspro.2016.07.055

[43] N. A. Majid-A, H. Mohammed y R. Sulaiman, «Students' perception of mobile augmented reality applications in learning computer organization.,» Procedia-Social and Behavioral Sciences, vol. 176, $\mathrm{n}^{\circ}$ 1, pp. 111-116, 2015. doi:10.1016/j.sbspro.2015.01.450

[44] S. Techakosit y P. Wannapiroon, «Connectivism learning environment in augmented reality science laboratory to enhance scientific literacy. ,..»Procedia-Social and Behavioral Sciences, vol. 174, $\mathrm{n}^{\circ}$ 1, pp. 2108 2115, 2015. doi:10.1016/j.sbspro.2015.02.009

[45] M. T. Coimbra , T. Cardoso y A. Mateus, «Augmented reality: an enhancer for higher education students in math's learning?,» Procedia Computer Science, vol. 67, $\mathrm{n}^{\mathrm{o}}$ 1, pp. 332-339, 2015. doi:10.1016/j.procs.2015.09.277

[46] J. Martín-Gutiérrez , F. Fabian , w. n. Benesova , M. D. Meneses y E. E. Mora, «.Augmented reality to promote collaborative and autonomous learning in higher education.,» Computers in Human Behavior, vol. 51, $\mathrm{n}^{\circ}$ 1, pp. 752-761, 2015. doi:10.1016/j.chb.2014.11.093

[47] B. Blevins, «Teaching Digital Literacy Composing Concepts: Focusing on the Layers of Augmented Reality in an Era of Changing Technology.,» Computers and Composition, vol. 50, $\mathrm{n}^{\circ} 1$, pp. 21-38, 2018. doi:10.1016/j.compcom.2018.07.003

[48] T. K. Huang, C. H. Yang, Y. H. Hsieh y J. Wang, «Augmented reality (AR) and virtual reality (VR) applied in dentistry.,» The Kaohsiung journal of medical sciences, vol. 34, $\mathrm{n}^{\circ} 4$, pp. 243-248., 2018 doi:10.1016/j.kjms.2018.01.009

[49] L. Del Bosque , R. Martinez y J. L. Torres , «Decreasing Failure in Programming Subject with Augmented Reality Tool.,» Procedia Computer Science, vol. 75, $\mathrm{n}^{\circ}$ 1, pp. 221-225, 2015. doi:10.1016/j.procs.2015.12.241

[50] T. Jeřábek , V. Rambousek y R. Wildová, «Specifics of visual perception of the augmented reality in the context of education.,» Procedia-Social and Behavioral Sciences, vol. 159, nº 1, pp. 598-604, 2014. doi:10.1016/j.sbspro.2014.12.432

[51] C. H. Chen , C. H. Ho y J. B. Lin , «The development of an augmented reality game-based learning environment.,» Procedia-Social and Behavioral Sciences, vol. 174, $\mathrm{n}^{\circ}$ 1, pp. 216-220, 2015. doi:10.1016/j.sbspro.2015.01.649

[52] A. Badías , I. Alfaro, D. González , F. Chinesta y E. Cueto, «Reduced order modeling for physically-based augmented reality.,» Computer Methods in Applied Mechanics and Engineering, vol. 341, $\mathrm{n}^{\circ}$ 1, pp. 5370., 2018. doi:10.1016/j.cma.2018.06.011

[53] J. Joo-Nagata, F. M. Abad , J. B. Giner-G y F. J. García-Peñalvo «Augmented reality and pedestrian navigation through its implementation in m-learning and e-learning: Evaluation of an educational program in Chile.,» Computers \& Education, vol. 111, $\mathrm{n}^{\circ} 1$, pp. 1-17, 2017. doi:10.1016/j.compedu.2017.04.003 
[54] M. Akçayır y G. Akçayır, «Advantages and challenges associated with augmented reality for education: A systematic review of the literature.,» Educational Research Review, vol. 20, $\mathrm{n}^{\circ}$ 1, pp. 1-11, 2017. doi:10.1016/j.edurev.2016.11.002

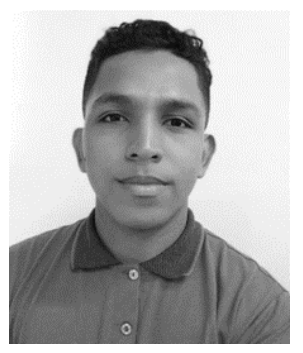

Yeikin Andres Mena Vargas. Born in Florencia-Caquetá, Colombia on December 16, 1999. Bachelor of the educational institution Antonio Ricaurte, currently studying eighth semester of the systems engineering career at the University of the Amazonia in the city of Florencia Caquetá in the country of Colombia.

He has developed work on non-academic dates in the fields of vegetable sales in stores, mobile repair technician, construction assistant and home delivery.

Systems engineer student.

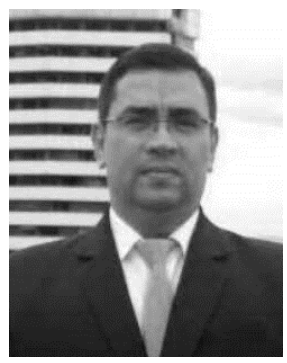

Edwin Eduardo Millán Rojas. Born in Florencia-Caquetá, Colombia in 1978. He studied Systems Engineering at the Francisco José de Caldas District University, an agreement with the University of Amazonia, graduated in 2004. He finished his studies in Software Engineering Specialization at the INCCA University of Colombia in 2006, graduated in the Master of Information and Communications Sciences at the Francisco José de Caldas District University in 2012, Doctor of Engineering from the Francisco José de Caldas District University in 2016.

$\mathrm{He}$ has worked since 2006 as a professor of Systems Engineering at the University of the Amazon, Associate Researcher according to the announcement of Colciencias,

director of the Research Group in Computer Science, Innovation and Technology of the University of the Amazon GITUA-.

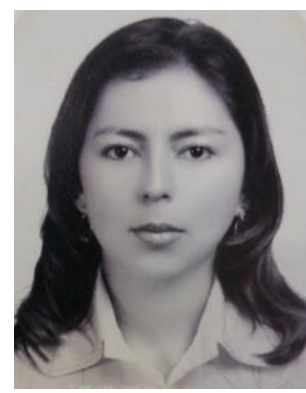

Cauca in 2019.

She has worked as a professor of Agroecological Engineering at the Universidad de la Amazonia, Associate Researcher according to call 781 of 2017 of Colciencias, director of the research group in agroecology and rural development GIADER-.
Verenice Sánchez Castillo. Born in Florence in 1980. She studied Agroecological Engineering at the University of the Amazon, graduated in 2002. She finished her Master's degree in regional studies in Environment and Development at the Iberoamerican University of Puebla in 2007, PhD in Anthropology Universidad del 